\title{
Altered Standards of Care for Health CARe Providers in The PANDEMic Influenza ${ }^{\dagger}$
}

\author{
Eleanor D. Kinney* \\ Heather A. McCabe ${ }^{* *}$ \\ Amy Lewis Gilbert ${ }^{* *}$ \\ Janna Jo Shisler ${ }^{* * *}$
}

TABLE OF CONTENTS

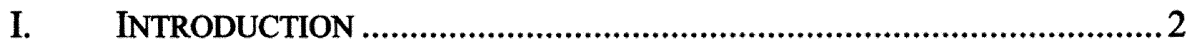

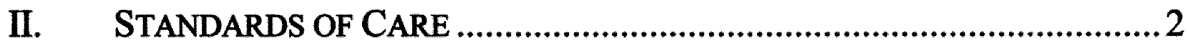

A. The Standard of Care under Current Law ................................ 2

1. Tort Standard of Care .......................................................... 3

2. Relevant State Medical Liability Laws ................................ 4

3. Regulatory Standards of Care ............................................ 5

B. Professional Development of the Content of the Standard of

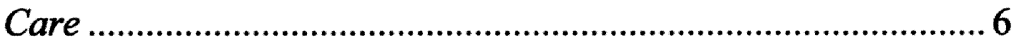

III. STATE AUTHORITY AND ALTERED STANDARDS OF CARE..................7

A. Setting the Altered Standard of Care for a Public Health Emergency......................................................................... 8

B. Modifying Liability Rules for Conduct during a Public Health

Emergency.............................................................................. 9

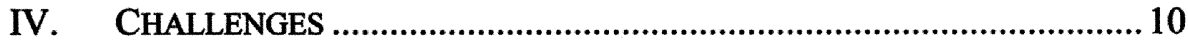

A. Triage Methodologies ........................................................... 10

t Notice: This Legal White Paper was prepared by the William S. and Christine S. Hall Center for Law and Health at the Indiana University School of Law - Indianapolis in conjunction with the Indiana University Center for Bioethics under contract with the Indiana State Department of Health as part of the project "Translating Ethics Advice into Practice: Public and Professional Outreach about Pandemic Influenza Planning in Indiana." The views expressed in this document are those of the authors and may not necessarily reflect the opinions of the Center for Bioethics, Hall Center for Law and Health, Indiana University, Clarian Health Partners, Inc., or the Indiana State Department of Health.

* Hall Render Professor of Law and Co-Director, William S. and Christine S. Hall Center for Law and Health at the Indiana University School of Law-Indianapolis; J.D. Duke University School of Law, M.P.H. University of North Carolina at Chapel Hill, M.A. University of Chicago, B.A. Duke University. The authors wish to thank many of whom assisted with the preparation of this white paper, including Ms. Jennifer Lemons and Ms. Margaret Ann Welsh.

** Director, Public Health Law Program, William S. and Christine S. Hall Center for Law and Health at the Indiana University School of Law-Indianapolis; J.D. Indiana University School of Law - Indianapolis, M.S.W. Indiana University School of Social Work, B.A. Indiana University

*** J.D. Indiana University School of Law - Indianapolis, M.P.H. Alabama University Birmingham, B.A. Boston University

**** J.D., LL.M., Indiana University School of Law-Indianapolis, B.A. Indiana University. 
B. Standard of Care for the Distribution of Vaccines and Antivirals.

C. Workforce Management and Altered Standards of Care ........... 13

1. Absenteeism of Employed Health Care Workers ................. 13

2. Use of Volunteer Health Care Professionals...................... 15

V. CONCLUSION 16

\section{INTRODUCTION}

Pandemic influenza will pose tremendous challenges to health care providers, state public health authorities, and the public. All will have to conduct business under the most adverse of circumstances. It will be difficult for providers to meet the customary legal standards of care imposed by state and federal regulatory authorities, as well as the common law tort system. This white paper will explore the legal issues associated with altered standards of care in pandemic influenza.

\section{STANDARDS OF CARE}

The concept of "standard of care" has several different meanings depending on the context. In medicine, public health, and the other health professions, "standard of care" refers to accepted standards acknowledged by the profession as defining acceptable and appropriate practice. Increasingly, these standards are developed by professional organizations, accrediting bodies, and government agencies in processes that vary greatly in their democratic characteristics. ${ }^{1}$ Development efforts are designed to clarify, establish, and codify professional standards of care in an organized and accessible manner. ${ }^{2}$

The concept of "standard of care" also has distinct meanings in the law. The term refers to a legal standard that must be followed to avoid liability, sanctions, or other legal consequences. Of note, the term "liability" is basically equivalent to legal accountability and, under civil law, generally involves the payment of compensation when such liability is found. Sanctions are imposed under regulatory or criminal law, wherein the latter imposes a range of remedies and penalties for violations of various legal standards of conduct established in criminal statutes.

\section{A. The Standard of Care under Current Law}

There are three primary legal standards of care that will be most relevant during pandemic influenza, particularly during the time of the surge. These are:

1. See Eleanor D. Kinney, Behind the Veil Where the Action Is: Private Policy and American, 51 ADMIN. L. REV. 154, 154-155 (1999).

2. See Eleanor D. Kinney, The Brave New World of Medical Standards of Care, 29 J. L. MED. \& ETHICS 323 (2001). 
(1) tort standards pertaining to nonconsensual conduct that apply to all people; (2) regulatory standards for both health care facilities and health professionals; and (3) criminal standards that apply to all people. For purposes of this paper, we will not discuss applicable criminal standards of conduct; although it should be noted that, following Hurricane Katrina, criminal prosecutions were brought against nursing home owners for negligent homicide in not moving their patients prior to the storm. ${ }^{3}$

\section{Tort Standard of Care}

In the tort standard of care, there are three predominant bases for liability: (1) liability for intentional conduct; (2) liability for negligent conduct, and (3) strict liability pertaining to certain activities. In intentional conduct, the tortfeasor is liable if he or she acts with "the purpose of producing that consequence" or "knows to a substantial certainty that the consequence will ensue from the person's conduct."4 Negligent conduct is a more complex concept and involves risk analysis with respect to one's conduct vis-à-vis another person. The Restatement (3rd) Torts emphasizes a balancing of the risk of injury if precaution is not taken versus the utility of taking precautions that may cost large amounts of money, stating:

A person acts with negligence if the person does not exercise reasonable care under all the circumstances. Primary factors to consider in ascertaining whether the person's conduct lacks reasonable care are the foreseeable likelihood that it will result in harm, the foreseeable severity of the harm that may ensue, and the burden that would be borne by the person and others if the person takes precautions that eliminate or reduce the possibility of harm. ${ }^{5}$

The third basis of tort liability is strict liability, which pertains to injuries from abnormally dangerous activities, ${ }^{6}$ and also from the manufacture and sale of defective consumer products. ${ }^{7}$ The basic theory of strict liability is that the in-

3. Adam Nossiter, Trial Starts for Owners of Nursing Home Hit by Storm, N.Y. TIMES, Aug. 17, 2007, available at $\mathrm{http}: / / \mathrm{www}$.nytimes.com/2007/08/17/us/nationalspecial/17nursing. html?partner-rssnyt\&emc=rss; see also Adam Nossitier, Nursing Home Owners Acquitted in Deaths, N.Y. TimeS, Sept. 8, 2007, available at http://www.nytimes.com/2007/09/08/us/ nationalspecial/08nursing.html? $\mathrm{fta}=\mathrm{y}$.

4. RESTATEMENT (THIRD) OF TORTS § 1: LIABILITY FOR PHYSICAL HARM (Proposed Draft No.1 2001).

5. Id. at $\S 3$.

6. Id. at $\S 24$.

7. Id. at $\S 1$. 
jured party need not prove fault on the part of the responsible party once causation is established.

\section{Relevant State Medical Liability Laws}

Most states have enacted statutes to address tort liability of health care professionals. $^{8}$ In these states, the applicable standard of care varies by jurisdiction. $^{9}$ In addition to setting the standard of care, states have also enacted statutes establishing pretrial procedural requirements, damage caps, and other reforms in an effort to reform the adjudication of malpractice cases. ${ }^{10}$ Indiana has had such a medical malpractice reform since 1975 . $^{11}$

A majority of states have adopted a "national" standard of care, but a significant minority still adheres to the "locality rule," which focuses on local customs to determine the appropriate level of care. ${ }^{12}$ The locality rule, developed over 100 years ago, was intended to protect rural and small town physicians who were presumed to be less informed and well equipped than colleagues in large cities. ${ }^{13}$ The standard of care enunciated under the strictest version of the locality rule measures the conduct of a physician against that of other physicians in the same field operating within the same community. ${ }^{14}$ Although most jurisdictions initially adopted the strict locality rule, many subsequently adopted a "modified locality rule" which is characterized as the degree of care, skill, and proficiency commonly exercised by ordinarily careful, skillful, and prudent

8. See, e.g., Ala. CODE $\S 6-5-540$ (2008), ALASKa STAT. $\S 09.55 .530$ (2008), ARIZ. Rev. Stat. ANN. § 12-561 (2008), ARK. CODE ANN. § 16-114-201 (2008), Colo. REv. STAT. § 13-64-101 (2007), DeL. CODE ANN. TIT. 18, § 6801 (2008), D.C. CODE ANN. $§ 16-$ 2801(LexisNexis 2008), FLA. STAT. § 766.101 (2008), GA. CODE ANN. § 9-9-60 (2008), HAW. REV. STAT. § 671-1 (2008), IDAHO CODE ANN. § 6-1001- (2008), ILL. COMP. STAT. § 5/2-1701 (2008), IND. CODE $\S 34-18$ (2006), IOWA CODE $\S 147.135$ (2008), KAN. STAT. ANN. $\S \S 60$ 3501 (2006), Ky. ReV. Stat. AnN. § 304.40-250 (West 2008), LA. Rev. Stat. AnN. § 40:1299.39 (2008), Me. Rev. Stat. AnN. tit. 24, § 2851 (2008), MD. Code ANN., HeAlth OcC. $\S 2 A-01$ (2008), MASS. GEN. LAWS ANN. ch. $231 \S 60$ B (West 2008), Mo. REV. STAT. § 538.205 (2008), MONT. CODE ANN. § 27-6-101 (2007), NEB. REV. STAT. § 44-2801 (2008), NeV. REv. STAT. § 41A.003 (2007), N.H. REv. Stat. ANN. § 507-C1 (2008), N.M. STAT. ANN. § 41-5-1 (West 2008), N.C. GEN. STAT. § 99-21.50 (2008), OHIO REV. CODE ANN. § 2323.41 (West 2008), 40 PA. STAT. ANN $\S 1303.501$ (West 2007), S.C. CODE ANN. $§ 15-79-110$ (2007), TenN. Code ANN. §§ 29-26-1 (2008), Tex. Civ. Prac. \& Rem. Code ANN. § 74.001 (Vernon 2007), UTAH CODE ANN. § 78-14-1 (2008), VA. CODE ANN. § 8.01-581.1 (2008), W. VA. CoDE $\S 55-7 \mathrm{~B}-1$ (2008), WIS. STAT. § 654.001 (2007). See also Michelle Huckaby Lewis, et al., The Locality Rule and the Physician's Dilemma: Local Medical Practices vs the National Standard of Care, 297 J. AM. MED. Ass'N 2633 (2007).

9. See statutes cited supra note 8.

10. National Conference of State legislatures, State Medical MalPRACtice ToRT LAws (2005), available at http://www.ncsl.org/standcomm/sclaw/medmaltorttable205.htm.

11. IND. CODE § 34-18 (2006).

12. Lewis et al., supra note 8, at 2633-34.

13. See, e.g., Vergara v. Doan, 593 N.E.2d 185 (Ind. 1992); Hall v. Hilbun, 466 So. 2d 856 (Miss. 1985) (both cases discuss the history of the locality rule and cite to applicable standards of care in various states at the time of publication).

14. Lewis et al., supra note 8, at 2634. 
physicians at the same time the treatment was provided and in similar localities. $^{15}$

States are moving toward a national standard of care that evaluates whether the physician has exercised the "care and skill which is expected of a reasonably competent practitioner in the same class to which he belongs acting in the same or similar circumstances." ${ }^{\text {"16 }}$ Most states adopting the national standard treat locality as one of several factors to be considered to determine whether a physician has acted reasonably under the circumstances. ${ }^{17}$ Some states, however, apply a variation of the "locality rule," or apply both standards of care depending on whether the physician is a specialist. ${ }^{18}$ The District of Columbia and twenty-nine states have adopted the national standard of care and twentyone states continue to maintain some version of the "locality rule."19

Until 1992, Indiana followed the modified locality rule. ${ }^{20}$ That year, in Vergara $v$. Doan, the Indiana Supreme Court established the following standard: "[A] physician must exercise that degree of care, skill and proficiency exercised by reasonably careful, skillful, and prudent practitioners in the same class to which he belongs, acting under the same or similar circumstances." ${ }^{21}$ In so doing, the Indiana Supreme Court adopted the national standard of care for Indiana.

\section{Regulatory Standards of Care}

The health care sector is one of the most regulated areas in the economy of the United States. A myriad of state and federal regulatory regimes govern both health care professionals and facilities to achieve a variety of regulatory objectives. These regulatory schemes involve both licensure and accreditation requirements.

Licensure and accreditation norms generally set regulatory standards for competence, and, increasingly, quality of services. Licensure for both professionals and facilities tends to both define the characteristics of the profession or facility and establish criteria and standards for meeting these definitive characteristics. Accreditation is basically the same as licensure except that the survey and certification function is carried out by a private organization. Often, as is the case with hospitals, accreditation by a private accrediting body, i.e., the Joint Commission on the Accreditation of Healthcare Organizations

15. Id.

16. Sara Rosenbaum, The Impact of United States Law on Medicine as a Profession, 289 J. AM. MED. Ass'N 1546, 1551 (2003) (quoting Shilkret v. Annapolis Emergency Hosp. Ass'n, 349 A.2d 245, 249-50 (Md. 1975)).

17. Lewis et al., supra note 8, at 2635.

18. Id. (See tbl. labeled Box. Interpretation and Categories of State Statutes and Case Law on Standard of Care).

19. Id. at 2634.

20. See Vergara, 593 N.E.2d at 187.

21. Id. 
("JCAHO"), will be deemed to meet the conditions of state licensure and also the conditions of participation for third party payers. ${ }^{22}$ The conditions required under licensure and accreditation may be one source to which a court looks as it determines whether or not a defendant has met the standard of care.

The federal Medicare program and joint federal-state Medicaid programs have an array of statutory and regulatory prescriptions governing health care providers to ensure that program beneficiaries receive high quality care for which payment is made. ${ }^{23}$ These standards are similar to licensure and accreditation standards in terms of the conduct they require on the part of providers. Given the experience in Hurricane Katrina, the Centers for Medicare and Medicaid Services ("CMS"), the agency within the Department of Health and $\mathrm{Hu}$ man Services ("DHHS") that administers the Medicare, Medicaid, and SCHIP programs, waived many of these standards because of the extraordinary difficulties compliance would have imposed on providers. ${ }^{24}$

Specifically, CMS waived liability for hospital emergency rooms under the Emergency Medical Treatment and Labor Act ("EMTALA") for transferring patients to other facilities for assessment if the original facility was located in an area where a public health emergency had been declared. ${ }^{25}$ CMS also waived certain Health Insurance Portability and Accountability Act ("HIPAA") privacy requirements so that providers could talk to family members about a patient's condition when patients were unable to grant that permission to the provider. ${ }^{26}$

\section{B. Professional Development of the Content of the Standard of Care}

It is important to appreciate that the ultimate source of these legal standards of care, particularly with respect to tort liability, are in fact professional norms. ${ }^{27}$ Since the 1980 s, the medical profession and its medical specialties have engaged in the development of more formal standards of care in all areas of medical practice. ${ }^{28}$

Further, the current standard of care in tort accommodates the fact that

22. See Eleanor D. Kinney, Private Accreditation as a Substitute for Direct Government Regulation in Public Health Insurance Programs: When is it Appropriate? 57 LAW \& CONTEMP. ProBs. 47, 50-57 (1994).

23. See Eleanor D. Kinney, The Medicare, Medicaid and SCHIP Programs Meet the Challenges of Public Health Emergencies, 58 ADMIN. L. REV. 559 (2006).

24. Kaiser Comm'n on Medicaid and the Uninsured, A Comparison of the Seventeen Approved Katrina Waivers (Jan. 2006), available at $\mathrm{http} / / / \mathrm{www} . \mathrm{kff} .0 \mathrm{gg} / \mathrm{medicaid} / \mathrm{upload} /$ 7420.pdf; see also Priscilla D. Keith, Access to Care Issues Consumers Continue to Face as a Result of Katrina, 2 A.B.A. HEALTH ESOURCE (Dec. 2005), available at http://www.abanet. org/health/esource/vol2no4.

25. 42 U.S.C. $\$ 1320 b-5(b)(3)(2009)$.

26. 42 U.S.C. $\$ \S 1320 b-5(b)(7)(A)(i)$ (2009); see also Standards for Privacy of Individually Identifiable Health Information, 45 C.F.R. $\$ \S 160-164$ (2003).

27. See Kinney, supra note 2.

28. See id. 
there may be legitimate variations in the conditions under which services are delivered with language such as "in like or similar circumstances."29 Certainly a state agency, with its authority to promulgate public health regulations, could establish standards of care by regulation if that agency's enabling legislation authorizes standard-setting activities. ${ }^{30}$

Thus, it is appropriate to rely on the flexibility of current standards to develop protocols in conjunction with stakeholders. To the extent that they have been developed in a fairly transparent and democratic process, model protocols will be authoritative in establishing the most appropriate standard of care. Indeed, governmental agencies have often adopted privately set standards in their regulatory programs. ${ }^{31}$

\section{STATE AUTHORITY AND ALTERED STANDARDS OF CARE}

The major sources of law that govern state public health matters are statutes that provide states the authority to protect and promote public health within the state. Most states also have specific statutes that authorize the governor of the state to declare an emergency and assume extraordinary powers to address the emergency. ${ }^{32}$ These statutes often immunize emergency and public health workers from liability for negligent conduct during the emergency. ${ }^{33}$

In 2006, Indiana revised its laws regarding public health and other emergencies to provide the governor with emergency powers, including rulemaking powers, and to waive liability for negligent conduct in certain instances. ${ }^{34} \mathrm{Un}$ der Indiana law, the Governor has the power to declare a state of emergency, which triggers authorizations to engage in many emergency response activities. $^{35}$

Additionally, it is important to note two model acts that are widely circulated. The first, the Model State Emergency Health Powers Act developed by the Center for Law and the Public's Health at Georgetown University School of Law and the Johns Hopkins School of Public Health in collaboration with the Centers for Disease Control and Prevention ("CDC"), ${ }^{36}$ has been somewhat

29. See Kinney, supra note 22.

30. See Eleanor D. Kinney, Administrative Law Approaches to Medical Malpractice Reform, 49 ST. LouIs U. L.J. 45 (2005).

31. See Kinney, supra note 1.

32. See Sharona Hoffman, Responders' Responsibility: Liability and Immunity in Public Health Emergencies, 96 GEo L.J. 1913, 1923 (2008); James G. Hodge, Jr. et al., The Legal Framework for Meeting Surge Capacity Through the Use of Volunteer Health Professionals During Public Health Emergencies and Other Disasters, 22 J. CONTEMP. HEALTH L. \& POL'Y 5, 23-24 (2005).

33. Hoffman, supra note 32 at 1946-50; Hodge, supra note 32 at 37-40.

34. IND. CODE § 10-14-3-12 (West 2008).

35. Id.

36. Model State Emergency Health Powers ACt $\$ \S 101-810$ (Proposed Official Draft 2001), available at http://www.publichealthlaw.net/MSEHPA/MSEHPA2.pdf; see also Lawrence O. Gostin, et al., The Model State Emergency Health Powers Act: Planning 
politically controversial. ${ }^{37}$ The second, the Turning Point Model State Public Health Act, ${ }^{38}$ is developed by a collaborative group of public health policy makers and academics funded by the CDC and The Robert Wood Johnson Foundation.

\section{A. Setting the Altered Standard of Care for a Public Health Emergency}

States do not require statutory authority to "alter" standards of medical treatment since such standards are established by professional organizations and individuals. Under current law, states can convene relevant stakeholders to discuss and develop an altered standard of care pursuant to the conventional processes for developing standards by these persons and entities. ${ }^{39}$

Under a state's authority to act in public health emergencies and to issue rules and orders to proceed in such emergencies, the state could issue an order recognizing that the previously developed protocol will be the altered standard of care in the public health emergency. Ostensibly, the governor could declare a previously developed protocol as the altered standard of care in the emergency at hand, although the governor need not take this step to assure that the protocols be authoritative. Nevertheless, such a rule- or even a declarationwould be useful in litigating cases and establishing the standard of care to be used in the situation. The Indiana Code gives the Governor the power to issue rules and orders in the event of a public health emergency. ${ }^{40}$ Similarly, the Turning Point Model Public Health Act accords such authority as well. ${ }^{4}$

The most effective way to confer authority on a protocol establishing an altered standard of care in subsequent litigation is to develop the protocol before the emergency - using the ideal process described above. Such a process would involve convening the major stakeholders from around the state to develop the protocol in a transparent and democratic process involving broad con-

for and Response to Bioterrorism and Naturally Occurring Infectious Diseases, $288 \mathrm{~J}$. AM. MED. Ass'N 622 (2002).

37. See Sue Blevins, The Model State Emergency Health Powers Act: An Assault on Civil Liberties in the Name of Homeland Security, HERITAGE FOUND. LECTURE 748 (2002), available at http://www.heritage.org/Research/HomelandSecurity/HL748.cfm. (Interestingly enough, this piece is a critique from the perspective of the conservative Heritage Foundation); George $J$. Annas, Response, Bioterrorism and Public Health Law, 288 J. AM. MED. Ass'N 2685 (2002); George J. Annas, Bioterrorism, Public Health, and Civil Liberties, 346 NEw. ENG. J. MED. 1337 (2002); see also Model St. EMERGENCY HeAlTH Powers ACT §§ 11-89 (Proposed Official Draft 2002), available at $\mathrm{http} / / / \mathrm{www} . n c s l . o r g /$ programs/health/modelact.pdf.

38. Model State Pub. Health Act §§ 1-101-9-106 (Proposed Official Draft 2003), available at $\mathrm{http}: / / \mathrm{www}$.turningpointprogram.org/Pages/pdfs/statute_mod/MSPHAfinal.pdf; see also Benjamin Mason Meier, et al., Contrasting Experiences of State Public Health Law Reform Pursuant to the Turning Point Model State Public Health Act, 122 PUB. HeAlth ReP. 559 (2007); James G. Hodge Jr., et al., Transforming Public Health Law: The Turning Point Model State Public Health Act, 33 J. L., MED. \& ETHICS 77 (2006).

39. See supra notes 22-26.

40. IND. CODE § 10-14-3-22 (2006).

41. Turning Point Model State Public Health Act § 6-102(d)(1) (2002); see also Model State Public Health EMERGenCy Powers ACt § 403(a)(1) (2001). 
sultation with interested parties and the public.

Also, the protocols would gain authority if they reflected consideration of other authoritative sources. The Agency for Healthcare Quality and Research has developed a useful guide for developing protocols for an altered standard of care. $^{42}$ The American Health Lawyers Association has also developed a tool to assist states in legal preparation for a public health emergency that specifically identifies key issues involved with developing protocols for altered standards of care. $^{43}$

\section{B. Modifying Liability Rules for Conduct during a Public Health Emergency}

State statutes that provide immunity from civil liability for health care providers and workers in emergency situations can greatly facilitate the implementation of altered standards of care. While such statutes are not necessary, they clarify that health care providers will not be civilly liable for negligence in a declared public health emergency. Such statutory provisions are important to provide legal "cover" in the event that stakeholders develop protocols for altered standards of care that depart from the standard of care for negligence in the usual business environment.

Once an emergency has been declared, Indiana law deems all emergency care workers, who are working in a governmental function not liable in tort for their actions, except where there is willful misconduct, gross negligence, or bad faith. $^{44}$ The Indiana Code also provides specific immunity for both health care workers and facilities as long as they refrain from willful misconduct and gross negligence. $^{45}$

Furthermore, Indiana law provides health care workers immunity from liability for negligence in public health emergencies if they are licensed health care professionals operating under circumstances of a declared disaster. ${ }^{46}$ These health care workers, however, are not immune from civil liability if damages result from gross negligence or willful misconduct. ${ }^{47}$ Facilities are also immune from civil liability in times of declared public health emergencies. ${ }^{48}$

42. AGENCY FOR HEALTHCARE RESEARCH AND QUALITY, ALTERED STANDARDS OF CARE IN MASS CASUALTY EVENTS, (April 2007), available at http://www.ahrq.gov/research/altstand/ altstand.pdf. See also AgENCY FOR HEALTHCARE RESEARCH AND QUALITY, PROVIDING MASS Medical CARE WITH SCARCE RESOURCES: A COMMUNITY PlanNING GUIDE(Feb. 2007), available at http://www.ahrq.gov/research/mcel.

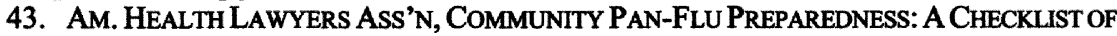
KEY LegAL IsSUES FOR HEALTHCARE PROVIDERs (2008), available at http://www.healthlawyers. org/Content/NavigationMenu/Public_Interest_and_Affairs/Public_Information_Series/PanFlu08.pdf.

44. IND. CODE § 10-14-3-15 (2006).

45. Id. § 34-30-13.5.

46. Id. \$ 34-30-13.5-1.

47. Id. § 34-30-13.5-2.

48. Id. § 34-30-13.5-3 
Similarly, the Turning Point Model Public Health Act contains provisions regarding tort liability of health care providers and workers. ${ }^{49}$

\section{CHALLENGES}

The challenges for the state, the providers, and the public will be legion during a pandemic, particularly during the pandemic's surge. The surge is the point in an epidemic when the most people are infected and the demand for medical resources and services is the greatest. DHHS has developed computer programs that states and providers can use to estimate the demand for services and resources during the surge. ${ }^{50}$ Also, hospitals customarily estimate what their surge capacity is for any public health emergency. ${ }^{51}$

Hospitals, nursing homes, home health care services, and other health care institutions are ill-prepared for a surge at any level, much less in the numbers expected in the event of pandemic influenza. Although many hospitals could operate at $125 \%$ percent capacity or more for up to 72 hours, most cannot maintain this level of service beyond 3 days. ${ }^{52}$ An additional important issue is whether alternative sites, such as hotels, schools, offices, and churches, will be used for the delivery of care during the surge and at other times. ${ }^{53}$ Such unorthodox facilities probably could not provide services at the customary standard of care.

\section{A. Triage Methodologies}

Triage in a public health emergency is the process by which first responders will sort victims to determine priority for treatment with those whose conditions will likely result in survival accorded medical care ahead of those unlikely

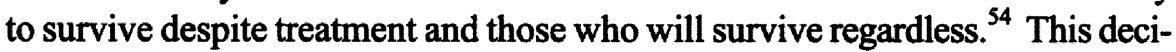
sion-making process will inevitably implicate legal doctrines pertaining to the standard of care. ${ }^{55}$ In the United States, health care and health law have traditionally focused on the individual patient. Generally, a physician owes a duty

49. TuRning Point Model State PUBlic Health Act § 6-105(b) (2002), supra note 41; see also MODEl StATE PUBlic HEALTH EMERGENCY POWERS ACt § 804 (b) (2001), supra note 41.

50. Ctr. for Disease Control, Pandemic Influenza Resources, Flu Surge 2.0, http://www. cdc.gov/flu/tools/flusurge/ (last visited June 17, 2008).

51. See J. Lee Jenkins, Robert E. O'Connor, and David C. Cone, Medicine Differentiating Large-scale Surge versus Daily Surge, 13 ACAD. EMERG. MED. 1169 (2006).

52. U.S. DEP'T. OF HEALTH \& HUMAN SERVS., AGENCY FOR HEALTHCARE RESEARCH AND QUALITY, AHRQ PUB. No. 06-0029, REOPENING SHUTTERED HosPITALS to EXPAND SURGE CAPACITY D-47 (2006), available at http://www.ahrq.gov/research/shuttered/shuthosp.htm.

53. Id.

54. George P. Smith, II, Re-Shaping the Common Good in Times of Public Health Emergencies: Validating Medical Triage, 18 ANNALS HeALTH L. 1, 9 (2009).

55. See James G. Hodge, Jr., Legal Triage during Public Health Emergencies and Disasters, 58 ADMIN. L. REV. 627 (2006). 
to provide the best care and seek the best outcome for each patient regardless of who is in the waiting room. Failure to provide such care may subject the practitioner to malpractice liability, professional penalties, and/or, in the most egregious cases, criminal sanctions. ${ }^{56}$ However, in the event of pandemic influenza and an unusually large number of ill patients, physicians will necessarily focus on maximizing population outcomes rather than improving the health of individuals. ${ }^{57}$ The medical community will shift to a public health orientation that focuses on ensuring the health and safety of the population as a whole. ${ }^{58}$ Significantly, the goal of providing optimal care to the population may require compromising best practices or providing less than optimal care to individual patients. This approach, ethically intolerable or legally suspect under normal conditions, may be necessary and appropriate under disaster scenarios. ${ }^{59} \mathrm{Con}$ sequently, pre-pandemic development of protocols for appropriate triage processes is essential. Protocols must address issues such as who gets access to limited resources like ventilators versus less intensive or palliative care.

Yet a 2006 literature review by a Canadian team of researchers found no current triage protocols for critical care in an influenza pandemic. ${ }^{60}$ The Canadian team and others have since proposed triage protocols that differ in many respects but offer policymakers a starting point for pre-pandemic planning. ${ }^{61}$ The proposals outline inclusion and exclusion criteria and identify the levels of treatment that are appropriate based thereon. Most focus on symptoms and avoid subjective criteria like age and lifestyle. These tools will assist first responders in making difficult decisions that allow for the optimal allocation of limited resources.

Experts agree that successful implementation of a triage methodology requires public discussion prior to the onset of a public health emergency. ${ }^{62} \mathrm{~A}$

56. See supra note 8, and accompanying text; see also Emest B. Abbott, Law, Federalism, the Constitution, and Control of Pandemic Flu, 9 ASIAN-PAC. L. \& POL'Y J. 18, 207-08 (2008).

57. Kristi I. Koenig, et al., Surging to the Right Standard of Care, 13 ACAD. EMERG. MED. 195 (2007).

58. Elizabeth Weeks, Lessons from Katrina: Response, Recovery and the Public Health Infrastructure, 10 DEPAUL J. HEALTH CARE L. 251, 257 (2007).

59. Id. at 284; see also Hillary R. Ahle, Symposium: Shaping a New Direction in Law and Medicine: An International Debate on Culture, Disaster, Biotechnology and Public Health: Anticipating Pandemic Avian Influenza: Why the Federal and State Preparedness Plans are for the Birds, 10 DePaul J. HeAlth CARE L. 213, 248-249 (2007).

60. Michael D. Christian, et al., Development of a triage protocol for critical care during an influenza pandemic, 175 CMAJ 1377 (2006).

61. Id. See Tia Powell et al., Allocation of Ventilators in a Public Health Disaster, 2 DisASTER MED. \& PuB. HeAlTH PREPAREDNESS 20 (2008); Daniel Talmor et al., Simple Triage Scoring System Predicting Death and the Need for Critical Care Resources During Epidemics, 35 CRIT. CARE MED. 1251 (2007); Kristy Challen et al., Physiological-Social Score (PMEWS) vs. CURB-65 to Triage Pandemic Influenza: A Comparative Evaluation Study Using Community-Acquired Pneumonia as a Proxy, 7 BMC HeALTH SERVS. RESEARCH 33 (2007). See also, John L. Hick and Daniel O'Laughlin, Concept of Operations for Triage of Mechanical Ventilation in an Epidemic, 13 ACAD. EMER. MED. 223 (2006).

62. See Ahle, supra note 59, at 248-249. 
public that is aware of and has the opportunity to participate in a forum addressing these very difficult issues will be less likely to view the decisions as unfair or motivated by suspected partiality. Although frightening to many people, the responsible path is to reach a public consensus on triage well before the state is confronted with a public health disaster.

Further, pre-epidemic planning will not only allow for discussion of the tort liability issues but will also allow for standards of care to be established in criminal law and anti-discrimination law. Specifically, criminal statutes and also the common law torts of reckless and intentional conduct will apply in cases in which decisions about access to life-saving treatment is withheld. ${ }^{63}$

Of note, if people perceive that additional criteria - such as social utility of individuals have been used in triage decisions - health care providers may be liable for discrimination under federal and state civil rights laws. ${ }^{64}$ Federal and state civil rights laws prohibit discrimination in public accommodations and access to government programs on the basis of race, religion, gender, and national origin. 65

\section{B. Standard of Care for the Distribution of Vaccines and Antivirals}

As with any other health care service, the decision to allocate vaccines and antiviral medications are governed by tort and regulatory standards of care. ${ }^{66}$ Thus, attention should be given to what are the appropriate protocols for the distribution of these products during pandemic influenza as part of the broader inquiry on altered standards of care.

As a legal matter, the federal government has the nearly exclusive authority to regulate drugs, biologics, and medical devices and does so through the Food, Drug and Cosmetic Act ("FDCA"). ${ }^{67}$ In national planning for pandemic influenza, the federal government, through its various emergency planning documents, has recognized a predominant federal role for the distribution of vaccines and biologics. ${ }^{68}$

Furthermore, federal law also addresses tort liability for injuries associated with pharmaceutical products including vaccines and medical devices. ${ }^{69}$ In re-

63. See supra notes 8-19 and accompanying text.

64. See Prohibition Against Discrimination or Segregation in Places of Public Accommodation, 42 U.S.C. $§ 2000$ a(a) (1999) (Americans with Disabilities Act, Title III requiring equal access to public places); 15 AM.JUR.2D Civil Rights $\S 223-231$ (2000) (describing state civil rights laws).

65. Id.

66. See supra notes 1-29 and accompanying text

67. 21 U.S.C. $\$ \S 331$ (2009).

68. See U.S. DEP'THEALTH\& HUMANSERVS.,HHSPANDEMICINFLUENZAIMPLEMENTATIONPLAN (Nov. 2006), available at http:/www.hhs.gov/pandemicflu/implementationplan.; see also U.S. DEP'T HEALTH \& HuMAN SERVS., Federal Planning \& Response Activities, http://www.pandemicflu.gov/ plan/federal/index.html\#implementation (last visited Mar. 11, 2009).

69. See Joseph Nicosia III, Note, Avian Flu: The Consumer Costs of Preparing for Global Pandemic, 18 Loy. CONSUMER L. REV. 479, 494 (2006). 
cent years, there have been several cases before the United States Supreme Court that have addressed whether federal regulatory law on labeling preempts state tort liability based on a failure to adequately warn of dangers associated with a medical product. $^{70}$ In 2006, the Food and Drug Administration ("FDA") asserted via drug labeling regulation that the FDCA preempted state tort law when it came to product labeling. ${ }^{71}$ The federal Turning Point Model State Public Health Act, if enacted, would immunize those administering vaccines from civil and criminal liability in a public health emergency. ${ }^{72}$

\section{Workforce Management and Altered Standards of Care}

Rampant absenteeism among health professionals during pandemic influenza could result in under-staffing to such an extent that ordinary legal standards of medical care will not be met. As an altered standard of care is developed, the issue of absenteeism during pandemic influenza should be addressed. In addition, a discussion of the appropriate use of volunteer health professionals during pandemic influenza and the creation of standards may help ensure a legal environment that will not discourage their much-needed assistance.

\section{Absenteeism of Employed Health Care Workers}

The federal government has estimated that pandemic influenza could affect $40 \%$ of the total workforce at its peak; that rate of absenteeism during a pandemic may well be immobilizing. ${ }^{73}$ Potential reasons for employee absenteeism during pandemic influenza include illness or death, mandatory or voluntary isolation or quarantine, necessary care of children when schools have been closed, an inability to get to work due to halted public transportation, obligations to care for a sick family member, or a fear of either contracting or spreading influenza at the workplace. ${ }^{74}$

In a 2006 survey of the U.S. population conducted by the Harvard School of Public Health, $57 \%$ of Americans said they would cooperate with public health officials if instructed to stay home from work, and $35 \%$ said they would

70. See Buckman Co. v. Plaintiffs' Legal Committee, 531 U.S. 341 (2001); WarnerLambert v. Kent, 128 S.Ct. 1168, 170 L.Ed.2d 512008 aff'd per curiam; Desiano v. WarnerLambert \& Co., 467 F.3d 85 (2d Cir. 2006); Riegel v. Medtronic, Inc., 128 S.Ct. 999 (2008); Levine v. Wyeth, 944 A.2d 179 (Vt. 2006), cert. granted, 128 S.Ct. 1118 (2008); Colacicco v. Apotex Inc., 521 F.3d 253 (3rd Cir. 2008).

71. Final Rule, Requirements on Content and Format of Labeling for Human Prescription Drug and Biological Products, 71 Fed. Reg. 3922 (Jan. 24, 2006) (21 CFR Parts 201, 314, and 601).

72. Turning Point Model State Public Health Act § 6-105, supra note 41.

73. U.S. DEP'TT OF LABOR, OCCUPATIONAL SAFETY AND HEALTH ADMIN., GUIDANCE ON PREPARING WORKPLACES FOR AN INFLUENZA PANDEMIC 7 (2007), available at http://www.osha.gov/Publications/influenza_pandemic.html.

74. Id. 
not. $^{75}$ Also, this survey reported that $22 \%$ of employed adults expressed concern that their employer would require them to work even if they were sick. ${ }^{76}$ More recently, in 2002, a national survey of physicians found that only $55 \%$ of respondents believed that they had an obligation to care for patients in an epidemic during which their own health might be endangered. ${ }^{77}$ Such fears of health professionals are not unfounded. In the 2003 SARS epidemic, health professionals were disproportionately infected with SARS in Vietnam, Hong Kong, and Canada. ${ }^{78}$

Many strategies have been proposed and/or implemented in response to this threat of health professional absenteeism. The American Medical Association ("AMA") has adopted several new policies focusing on physician responsibilities during such emergency situations. ${ }^{79}$ One AMA policy, adopted in June 2004, states that "physicians have an obligation to provide urgent medical care during disasters ... even in the face of greater than usual risks to their own safety, health or life." ${ }^{80}$ This responsibility is limited, however, by the recognition that "the physician workforce ... is not an unlimited resource ... [and] physicians should balance immediate benefits to individual patients with ability to care for patients in the future." 81

Different methods are being utilized to attempt to address this issue. In Maryland, for example, health professionals are required to report to work during medical emergencies or risk imprisonment. ${ }^{82}$ The Model State Emergency Health Powers Act authorizes licensure revocation by requiring that health professionals provide care during a public health emergency "as a condition of licensure, authorization, or the ability to continue to function as a health care provider." ${ }^{83}$ Another approach is to offer incentives discouraging absenteeism. In Vietnam and Canada, for example, health care workers received additional pay for caring for SARS patients. ${ }^{84}$

75. Press Release, Harvard School of Public Health, In the Case of an Outbreak of Pandemic Flu: Large Majority of Americans Willing to Make Major Changes in Their Lives, (Oct. 26,2006), available at http://www.hsph.harvard.edu/news/press-releases/2006-releases/ press10262006.html.

76. Id.

77. G. Caleb Alexander and Matthew K. Wynia, Ready and Willing? Physicians' Sense of Preparedness for Bioterrorism, 22 HEALTH AFF. 189, 195 (2003); see also Ariel R. Swartz, Doubtful Duty: Physicians' Legal Duty to Treat During An Epidemic, 60 STAN. L. REV. 657 (2007).

78. Mark A. Rothstein, Are Traditional Public Health Strategies Consistent with Contemporary American Values? 77 TEMP. L. REV. 1775, 185-86 (2004).

79. Am. Med. Assoc., OpINion 9.067: Physician Obligation IN Disaster PREPAREDNESS \& RESPONSE (2004), available at http://www.ama-assn.org/ama/pub/physicianresources/medical-ethics/code-medical-ethics/opinion9067.shtml

80. Id.

81. Id.

82. Univ. of Md. Ctr. for Health \& Homeland Sec., Maryland Public Health EMERGENCY PREPAREDNESS LEGAL HANDBOOK (2005), available at http://www.umaryland. edu/healthsecurity/docs/Handbook\%209-9-05.pdf.

83. MODEl STATE EMERGENCY HEALTH POWERS ACT § 608(a), supra note 36.

84. See Rothstein, supra note 78, at 186. 
Absent legislative or regulatory action at the federal and state level, there is a huge body of law regulating employment relationships that will apply in the event of pandemic influenza, just as it applies at any time. Laws governing employment and worker protections include wage and hour policies, workers compensation, discrimination and other matters that are integral to the employment relationship. These laws may work together to reduce the legal complexities related to absenteeism and limit employee violations of related workplace policies.

\section{Use of Volunteer Health Care Professionals}

There are three important legal issues with the use of volunteer professionals: provider liability for volunteer conduct in the delivery of services; provider liability for injury to volunteer professionals; and the portability of out-ofstate volunteer professional licenses. These issues are analyzed extensively in an article by Professor James G. Hodge and colleagues. ${ }^{85}$

Following the terrorist attacks of September 11, 2001, Congress authorized the DHHS to fund the Emergency System for Advanced Registration of Volunteer Health Professionals ("ESAR-VHP"). ${ }^{86}$ Under this system, thirtyseven jurisdictions currently have operational advance registration systems, and the remaining jurisdictions have plans to become fully operational in the future. $^{87}$

Although ESAR-VHP may allow for the rapid identification of qualified volunteers, licensure requirements will still have to be relaxed in order for volunteers to practice. Most states and territories have agreed to provide for reciprocity of licensure between jurisdictions for healthcare professionals. ${ }^{88}$ In addition, the Emergency Management Assistance Compact ("EMAC")developed by the National Emergency Management Association- allows for reciprocity between member jurisdictions regarding the credentialing of volunteers for the duration of an emergency. ${ }^{89}$ The Turning Point Model State Public Health Act also has extensive provisions regarding the licensure and appointment of health care personnel during a public health emergency. ${ }^{90}$ Indiana law specifically allows for volunteer workers from other jurisdictions to practice

85. James G. Hodge, Jr., at al., Volunteer Health Professionals and Emergencies: Assessing and Transforming the Legal Environment, 3 BIOSECURTY \& BIOTERRORISM: BIODEFENSE STRATEGY, PRACTICE \& SCIENCE 216 (2005).

86. See 42 U.S.C. $\$ 300 \mathrm{hh}-10$ (2009); 42 U.S.C. $\$ 247 \mathrm{~d}-3 \mathrm{a}$ (2009).

87. U.S. DeP'T. OF HeAlth \& HUMAN SERVS., OfFICE OF THE ASSISTANT SEC'Y FOR Preparedness \& Response, FY 2009 Online Performance APPendix, available at http://www.hhs.gov/budget/09budget/asprfy09opa.pdf.

88. James D. Hodge et al., Risk Management in the Wake of Hurricanes and Other Disasters: Hospital Civil Liability Arising from the Use of Volunteer Health Professionals During Emergencies, 10 MICH. ST. J. MED. \& LAW 57, 68 (2006).

89. Model INTRASTATE MUTUAL Aid Legislation art. 6 (Nat'l Emergency Mgmt. Assoc. 2004), available at http://www.emacweb.org/?1546.

90. Turning Point Model STAte Public Health Act § 6-104 (d), supra note 41. 
and authorizes the use of the Indiana Worker's Compensation program in the event of volunteer injury. ${ }^{91}$ In addition, the Indiana Code allows for mutual aid agreements, both among counties and between states. ${ }^{92}$

\section{CONCLUSION}

Recent events, such as Hurricane Katrina and 9/11, have highlighted the importance and necessity of preparing for emergencies and disasters before they occur. The thoughtful preparation of altered standards of care plans prior to pandemic influenza is necessary to ensure that health care providers are empowered to act in their communities' best interests. Such providers will be operating under significant duress in the wake of a pandemic, and the provision of legal guidance and protection is necessary to ensure that they act rapidly to mitigate the spread of infection and adequately care for the afflicted.

91. IND. CODE § 10-14-3-15 (2006).

92. Id. § 10-14-3-16. 